\title{
Weak Links and Countermeasures in Project Cost Control
}

\author{
Ke Liu ${ }^{1, a, *}$ \\ ${ }^{1}$ Complete Project Research, Logistics University of Chinese People’s Armed Police Force, Tianjin, China \\ a502335602@qq.com \\ *corresponding author
}

Keywords: Barracks Construction, Cost Management, Suggestion

\begin{abstract}
Cost management, as an important component of construction project management, has a great impact on the construction and use efficiency of the project. In fact, it also restricts the overall goal of project construction. First, the paper summarizes the basic situation of the construction project cost control. Secondly, it summarizes the main problems in the project cost control of construction. Finally, it puts forward the measures to improve the cost management of the construction project.
\end{abstract}

\section{Introduction}

In recent years, the pace of capital construction has been accelerating, but there are still some weak links in the process of project cost control, which need to be further standardized and perfected, so as to effectively strengthen the construction project control, control the project cost and improve the investment efficiency.

\subsection{Barracks construction project cost management basic situation}

In recent years, with the popularity of computer and Internet technology and application, the project cost management of the construction project has developed. For a long time, the construction project cost control and management work has its own unique experience and system process. In the project decision-making stage, the construction project basically carried out the feasibility study, and on this basis to strengthen the construction project decision-making consultation, project evaluation and project demonstration; in the project construction implementation stage, strictly promote the bidding work, follow the construction project tender The bidding method and the contract law, the engineering design, construction, construction supervision contract are open tender, preferred selection of cooperative units; in the construction project completion stage, the project has been completed in time to finalize the project, settlement audit, and the preparation of financial final accounts report.

\section{The weak links of current project cost control}

\subsection{The feasibility study report is not complete and detailed}

The depth of investment estimates is not enough, and even the lack of leakage, resulting in investment funds difficult to meet the actual needs.

\subsection{The design process of the importance of the economy is not enough}

Lack of understanding of cost control, there is still too much to pursue security, solid and ignore the cost of the phenomenon of cost, and some works "fat beam, fat column" situation is the most important problem.

\subsection{Project bidding phase of the management and control is not standard}

Bidding agency capacity is not professional, and the quality is not high, the preparation of the bill of quantities is not accurate to invite the main tender. And we also can see the company are lack 
of transparency for the public. Tender units one-sided pursuit of their own interests, the use of various improper means of malicious competition Occurred, the use of market competition to control the cost of the project is not obvious.

\subsection{One-sided emphasis on project progress affect the project cost}

The preliminary preparatory work of the project should go through a series of processes such as preliminary design, budget, project, review, preparation of construction drawing, bidding, signing of contract and so on. But in the actual construction process often due to various objective factors, one-sided pursuit Project progress, not only did not really speed up the progress of the project, but to effectively control the project cost to bring a variety of negative effects.

\subsection{The terms of the contract lack of scrutiny and research}

Various risk factors and settlement principles and other contracts in the core content of the agreement is not clear, involving the duration, quality and other liability for breach of contract provisions of the degree of attention is not enough. The construction unit in the tender made concessions promised at the time of signing the contract was missing, and even the contract part of the terms and contrary to the contents of the tender, to the project settlement to bring a variety of risks.

\subsection{There are still some randomness in the project construction and management}

Free to improve the construction standards, increase the function, free to design changes, project visa and the main unit price approval procedures are not standardized.

\section{The control of the project cost}

\subsection{From the investment estimation stage to strengthen the project cost control}

First of all, we should ensure that the feasibility of the preparation of engineering feasibility study report. We should choose a higher credit, reputable companies to participate in this work. Second is to estimate the investment to provide the quantitative indicators to meet the construction of the regular data, to find out the impact of the cost of weight indicators to be analyzed to seize the main contradictions, timely adjustment, and to the previous large projects can be Research reports and review reports to conduct a summary analysis, so that the feasibility study report can be missed, the maximum funding for construction.

\subsection{From the design stage to strengthen the project cost control}

\subsubsection{Focus on design optimization}

To overcome the concept of heavy construction light design, in the review of the design unit design, attention to design optimization, the use of various indicators for analysis and comparison, in particular, should proceed from the actual situation of the troops to improve investment efficiency as the premise, according to the economic strength, To be sure enough to apply, the economy is reasonable, easy to operate the design.

\subsubsection{Promote quota design}

With the approved feasibility study report investment estimates to control the initial design, and in accordance with the approved preliminary design estimates to control the design of technical and construction plans, while the professional to ensure the use of functional requirements to meet the premise of the allocation of investment limits to control the design, Strict control of unreasonable changes to ensure that the total amount of investment was broken.

\subsubsection{Adopt contractual measures actively}

In view of the economic concept of the designer are weak, the design changes are arbitrary. We should be in the design contract economic terms, increase the design of the revised cost limit, such 
as design changes in the cost of a certain proportion of the contract, the deduction should be the corresponding design warranty

\subsection{From the bidding phase to strengthen the project cost control}

Bidding is a key link in the construction of the project, the construction unit can be selected in the bidding stage of qualified construction enterprises to ensure the quality of the project, and the corresponding market price competition, effective control of project cost.

\subsubsection{Prepare a reasonable tender control price}

Due to the lack of construction units of the corresponding professional and technical strength, the corps in the past infrastructure projects in the bidding process are organized by the tender agency units to prepare the bill of quantities and tender control price, and because part of the tender agent is not strong sense of responsibility, Designated construction units for the preparation, resulting in part of the infrastructure projects clearing the situation is more prominent budget. Therefore, the corresponding policies should be formulated to change the pattern of past ex post supervision and to supervise the construction process.

\subsubsection{To enhance the transparency of bidding work}

Make full use of the market competition to control the project cost, to prevent the public tender for the community can be considered as a classified project, designated construction units, and even the formation of a monopoly, and ultimately difficult to control the project cost.

\subsubsection{The preparation of tender documents to focus on the cost of control elements}

For labor, materials, mechanical fees and fees to strengthen the control, because in the current pricing standards, the tender when the people, materials, machine and the fee will form a constant integrated unit price, will directly affect the project cost.

\subsubsection{To be preferred to the tender agent}

Select the tender unit not only to examine the unit qualification, reputation, but also to examine the tender, the unit sent professionals have sufficient experience and ability to supervise the tender personnel to comply with professional ethics, to prevent the black box operation, to ensure fair and impartial work And public.

\subsection{Control the cost of the project from the stage of conclusion of the contract}

To standardize the contract management, similar projects should use the agreed text of the contract, the content should be complete, concise, rhetoric, the main terms of the tender documents, the tender unit commitment should be reflected in the contract, the expected risk agreed to Clear, the expression should be clear, the construction period and quality requirements should be objective reality, there must be a clear breach of contract and incentive measures to effectively avoid the contract risk.

\subsection{Control the project cost from the construction stage}

Strengthen the construction process management, standardize the construction process of the project that the cost of the project cost of the flow of approval procedures, including design changes, engineering visas, technical core orders, professional subcontracts, the main material price approval, etc., to ensure that the project cost Get effective control.

\section{Conclusion}

Project cost is the important content of the control of barracks construction project. The merits of cost management work is always the core component of whether the investment target of barracks project can be realized. At present, the barracks construction project in the implementation process there are still some cost management issues, for the existing problems inductive analysis, and to put 
forward the relevant improvement measures, and strive for the construction project cost management work to provide some reference.

\section{References}

[1] Xiong Yang, Derong Liu, Qinglai Wei, Ding Wang. Guaranteed cost neural tracking control for a class of uncertain nonlinear systems using adaptive dynamic programming [J]. Neurocomputing, 2015,:

[2] Renming WANG, Thierry Marie GUERRA, Alexandre KRUSZEWSKI, Juntao PAN. GUARANTEED COST CONTROL FOR UNCERTAIN DISCRETE DELAY T-S FUZZY SYSTEM [J]. IFAC Proceedings Volumes, 2007, 40(21):

[3] Ugur Şahin,Ulviye BaŞer. Delay-Dependent Guaranteed Cost Control for T-S Fuzzy Descriptor Systems with Time Varying Delay[J]. IFAC Proceedings Volumes, 2009, 42(14):.

[4] Hiroaki Mukaidani, Yasuyuki Takato,Yoshiyuki Tanaka,Koich Mizukami. THE GUARANTEED COST CONTROL FOR UNCERTAIN LARGE-SCALE INTERCONNECTED SYSTEMS [J]. IFAC Proceedings Volumes, 2002, 35(1): 